\title{
Perspective
}

\section{Monkeypox, Marshfield Clinic and the Internet: Leveraging Information Technology for Public Health}

\author{
Kurt D. Reed, MD, Department of Pathology, Marshfield Clinic, Marshfield, Wisconsin \\ and the Clinical Research Center, Marshfield Clinic Research Foundation, Marshfield, Wisconsin
}

REPRINT REQUESTS:

Kurt D. Reed, MD

Clinical Research Center

Marshfield Clinic Research Foundation

1000 North Oak Avenue

Marshfield, WI 54449

Telephone: $715-389-5478$

Fax: 715-389-3319

Email: reed.kurt@mcrf.mfldclin.edu

\section{KEYWORDS:}

Monkeypox; Internet; Public health
In the middle of May 2003, a three and a half year old girl from central Wisconsin presented for treatment of an infection that occurred after bites to her hands from a pet prairie dog. It appeared at first that this was just another case of bacterial cellulitis associated with an animal bite. The cellulitis would quickly resolve with antibiotics. This is a common scenario for physicians of Marshfield Clinic, a multi-specialty group practice that serves a largely rural population. However, as so often occurs in medicine, the seemingly straight-forward case takes an unexpected turn, and over the coming weeks a remarkable, if not thoroughly bizarre story unfolds.

The final chapter was unexpected and alarming to anyone even remotely interested in public health. Monkeypox virus, an Old-World cousin to smallpox and never before seen in humans in the Western Hemisphere, had made its way into the United States through rodents imported from western Africa. ${ }^{1,2}$ The final tally would be 37 confirmed and 72 suspect human cases in six states. ${ }^{3}$ Embargoes on the importation and sale of rodents from Africa were rapidly implemented by state and federal agencies. Serious concerns were raised about the widespread practice of owning exotic animals as pets. ${ }^{4}$

The investigation and research into the type and source of the monkeypox outbreak required an enormous expenditure of time and money. In the end the monkeypox outbreak was contained due to the combined effort of a large number of physicians, clinical laboratories, local and state public health departments, the Centers for Disease Control and Prevention (CDC), and numerous other state and federal agencies.

As an infectious disease pathologist embedded in the initial phase of the investigation, it was enlightening to observe first hand the intensity of our nation's public health response to a newly introduced virus. Very early on it became apparent that the Internet and other communication technologies would play a critical role in piecing this strange puzzle together.

To narrow the differential diagnosis, Marshfield Clinic dermatologists, John Melski and Erik Stratman, distributed via e-mail, high quality digital images of the child's skin lesions to clinical and laboratory consultants. Shortly thereafter, the mother of the index case experienced similar skin eruptions. My laboratory was asked to perform virus culture and electron microscopic (EM) analysis of the biopsy taken from the mother. The combined results of viral cultures and EM suggested an infection due to an Orthopoxvirus, an unusual diagnosis and one that was difficult 
to reconcile with the clinical history. Just as with the clinical photographs, the histologic, cell culture and EM images were digitized, annotated, and formatted for electronic distribution.

In the interim, the situation intensified as information was received from other healthcare providers in Southeastern Wisconsin. Similar cases of vesiculopustular eruptions were occurring among patients exposed to ill prairie dogs. It soon became apparent that the cases being treated at Marshfield were not isolated events. In an attempt to determine the etiology and extent of the outbreak Dr. Jeffery Davis of the Wisconsin Department of Health and Family services convened a teleconference on June 5, 2003, that linked physicians with representatives of local, state and federal agencies. During this critical juncture of the investigation, Dr. Melski, head of clinical informatics at Marshfield Clinic, and Dr. Salah Qutaishat, a senior infection control practitioner at Saint Joseph's Hospital in Marshfield, suggested that placing the clinical and laboratory images of the infection on a web site could significantly expedite the investigation (figure 1).

The results of that decision were extraordinary. In less than one hour, scientists from across the United States were able to have a clear view of the situation in Wisconsin and plans were made to ship specimens to the CDC Poxvirus Laboratory for analysis. The diagnosis of monkeypox was confirmed just two days later; however, the value of the clinical and laboratory images continued to increase over the next several weeks. As public health agencies worked to find additional cases and limit the extent of the outbreak, the Marshfield Clinic web site became a focal point for educating healthcare providers and the general public about the clinical and laboratory aspects of monkeypox infections. During the first two months of the investigation the Marshfield Clinic monkeypox web site received over 400,000 page hits, and the site continues to have significant activity nearly seven months later.

Emerging infectious diseases are an ever increasing problem across the globe and there are numerous other examples of the real value the Internet provides in helping to control communicable diseases. When an outbreak of conjunctivitis was identified at Dartmouth College in 2002, health officials were able to rapidly collect information by means of surveys delivered over the Internet. This allowed data to be analyzed within just a few days of the outbreak. The information speeded the formulation of a rational strategy for containment of the epidemic. ${ }^{5}$ Similarly, the recent identification of severe acute respiratory syndrome (SARS) highlights the utility of having a global tracking system for diseases where cases occur over several health jurisdictions on multiple continents simultaneously. ${ }^{6}$

Although the advantages of a rapid global communication system for healthcare seem obvious, there are inherent limitations as well. Medical information placed on public web sites must be accurate. Medical journals that use the
Internet to expedite publication of scientific studies must maintain a rigorous peer review process. ${ }^{7,8}$ Institutions sponsoring medical web sites should work together to give healthcare providers and the public a consistent and balanced message. To do otherwise will invite the potential for more harm than good should the public unnecessarily overreact or panic to reports of disease outbreaks.

Public health is beginning to reap the benefits of the significant investment made by medical organizations over the past several decades into information technology. The recent monkeypox outbreak provided Marshfield Clinic with an unexpected opportunity to test systems that were many years in the making. The results were gratifying. Unfortunately, we live in the harsh reality of a world where the next epidemic is just around the corner and the next challenge may be even greater. As we go forward we must continue to take full advantage of the information systems currently in place to support public health and continue to look for innovative ways to leverage new technologies as they become available.

\section{ACKNOWLEDGMENTS}

The author is indebted to Drs. John Melski and Erik Stratman for providing the clinical photograph, Adam Hable for information on web site activity, Dr. Kathyrn Kolquist for the light microscopic image, and Donald Stoiber for the electron micrographs.

\section{REFERENCES}

1. Multistate outbreak of monkeypox -Illinois, Indiana, and Wisconsin, 2003. MMWR (Morb Mortal Wkly Rep) 2003;52:537-540.

2. Reed KD, Melski JW, Graham MB, Regnery RL, Sotir MJ, Wegner MV, Kazmierczak JJ, Stratman EJ, Li Y, Fairley JA, Swain GR, Olson VA, Sargent EK, Kehl SC, Frace MA, Kline R, Foldy SL, Davis JP, Damon IK. The detection of monkeypox in humans in the Western Hemisphere. N Engl J Med 2004;350:342-350.

3. CDC. Monkeypox: Report of Cases in the United States, Data reported to CDC as of July 30, 2003. http://www.cdc.gov/od/oc/media/mpv/cases.htm

4. CDC. Joint order of the Centers for Disease Control and Prevention and the Food and Drug Administration, Department of Health and Human Services. 11 June 2003. http://www.cdc.gov/ncidod/monkeypox/pdf/embargo.pdf

5. Pryor JN, Martin MT, Whitney CG, Turco JH, Baumgartner YY. Rapid response to a conjunctivitis outbreak: the use of technology to leverage information. J Am Coll Health 2002;50:267-271.

6. Tsang KW, Ho PL, Ooi GC, et al. A cluster of cases of severe acute respiratory syndrome in Hong Kong. N Engl J Med 2003;348:1977-1985.

7. Woodall J. Official versus unofficial outbreak reporting through the Internet. Int J Med Inf 1997;47:31-34.

8. Drazen JM, Campion EW. SARS, the Internet, and the Journal. N Engl J Med 2003;348:2029. 
A

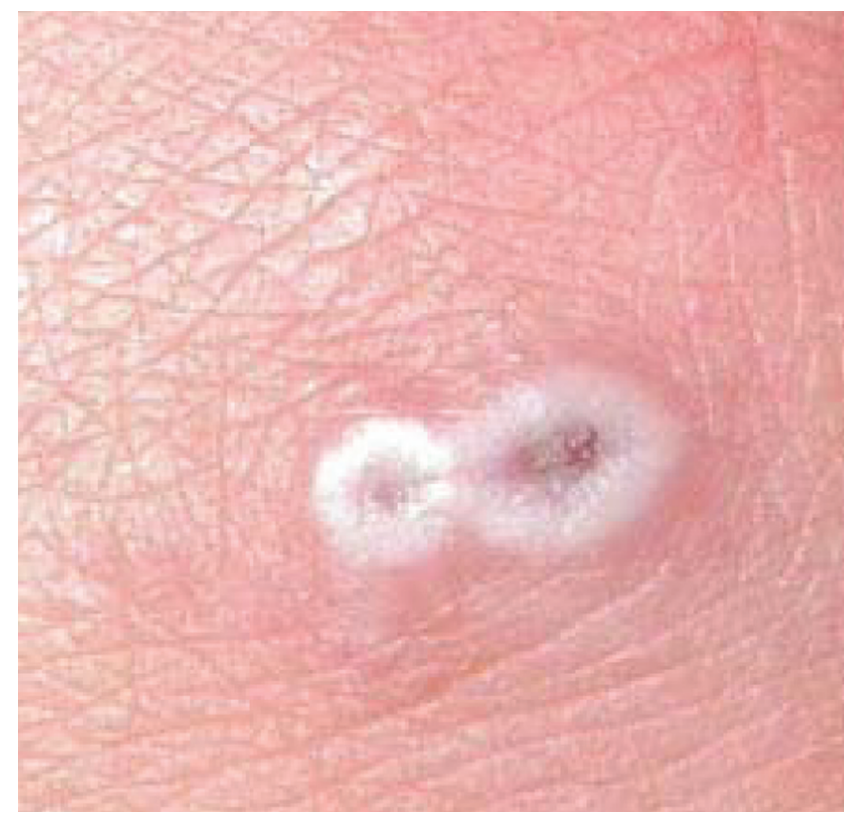

C

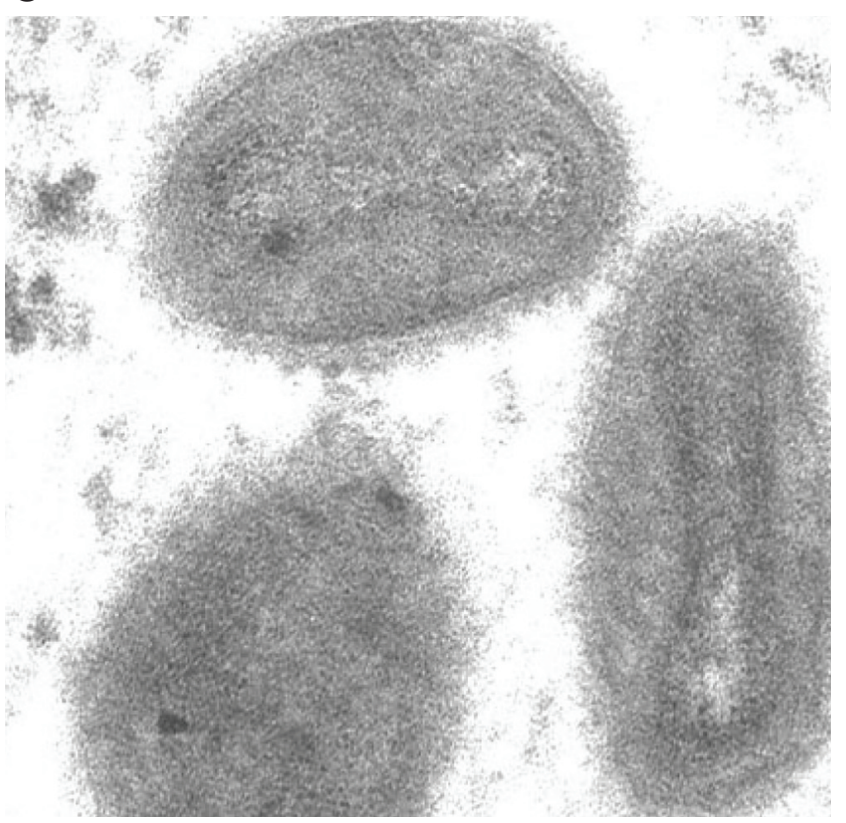

B

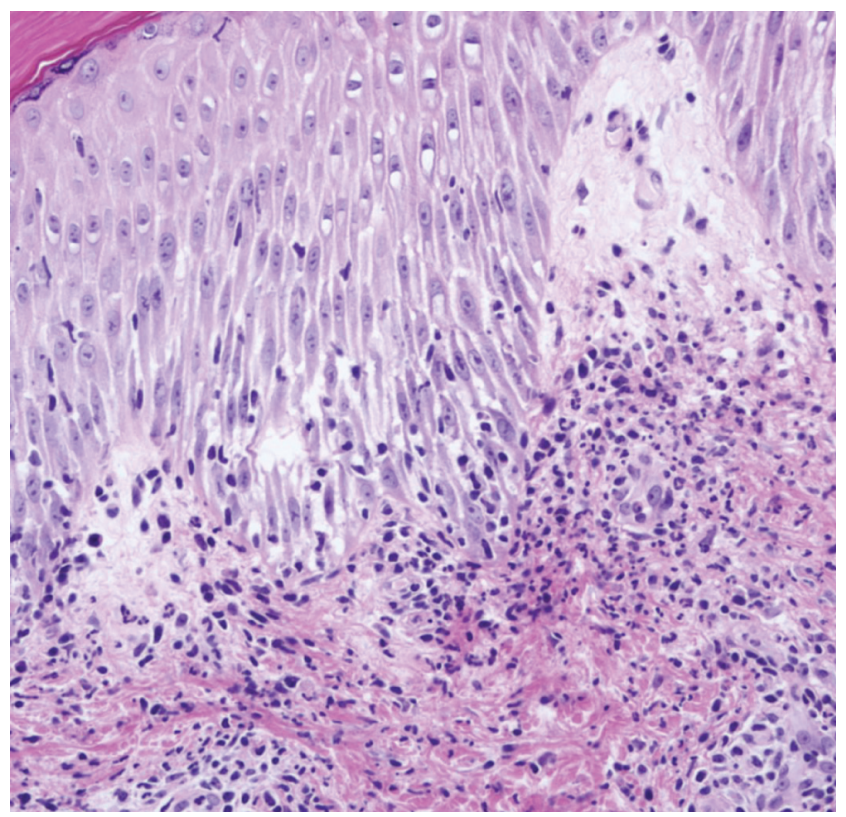

D

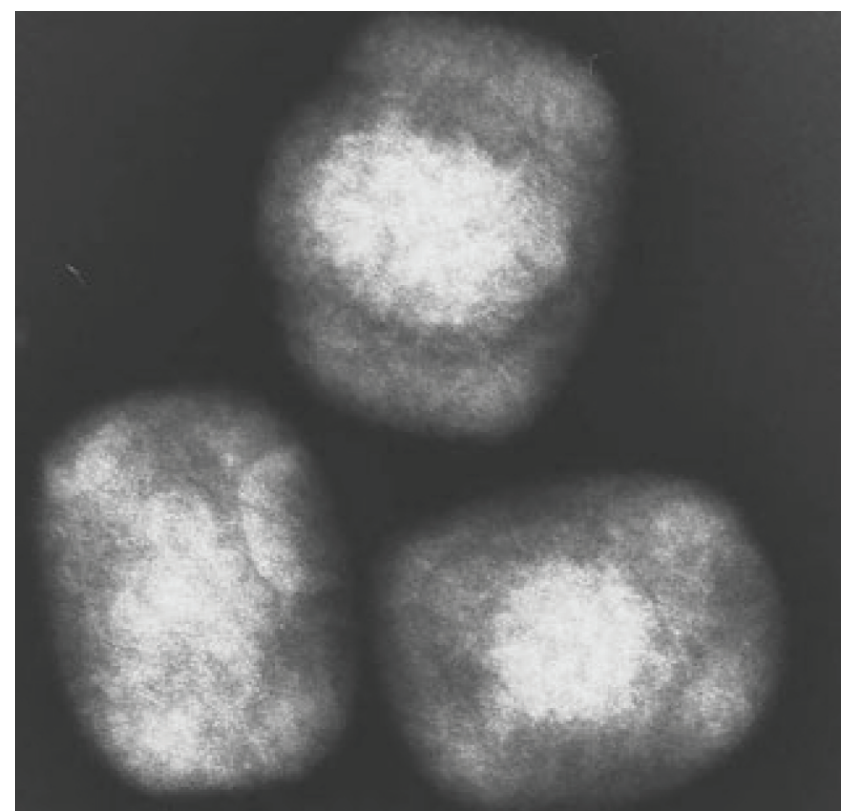

Figure 1. Examples of photographs that were digitized, annotated and formatted for electronic distribution during the 2003 outbreak of human monkeypox in Wisconsin. The Marshfield Clinic web site containing these images had over 400,000 page hits during the first eight weeks of the outbreak investigation.

A. Clinical photograph of a primary inoculation skin lesion at the site of a previous scratch.

B. Light microscopic appearance of the inflammatory response to monkeypox virus infection of the skin.

C. Transmission electron microscopy of a skin biopsy demonstrating the dumbbell-shaped inner cores of virus particles characteristic of poxviruses.

D. Negative stain electron microscopy of a cell culture supernatant showing several brick-shaped particles of monkeypox virus. 